\title{
THE IMMEDIATE PROGNOSIS OF CARDIAC INFARCTION IN DIABETICS
}

\author{
R. J. JaRretT, B.A., M.B., B.Chir. \\ Funior Lecturer, Department of Pharmacology, Guy's Hospital Medical School, London, S.E. I \\ Formerly Registrar, Diabetic Department, King's College Hospital, London, S.E.5
}

Most textbooks do not comment upon the mortality rate of cardiac infarction in diabetics, although ischæmic heart disease is said to be common amongst them. Paul Wood (1956), however, quotes diabetes as a factor adversely affecting the prognosis following cardiac infarction. This statement is presumably based upon the findings of Mintz and Katz (1947), who reviewed a series of cases seen between 1940 and 1945. Of their 572 cases, 85 were diabetic. These authors correlated mortality rate and sex, and found it to be $18.6 \%$ of non-diabetic males against $27.8 \%$ of diabetic and $28.9 \%$ of non-diabetic females against $36.7 \%$ of diabetic. Later, Katz, Mills and Cisneros (1949), following up the same series, stated that the long-term survival of a diabetic, if alive after two months, is the same as that of a non-diabetic. However, Cole, Singian and Katz (1954) found that diabetes did not affect the immediate outcome, but did shorten long-term survival. Similarly, Doscher and Poindexter (1950), in their own series, found the overall acute mortality was $15.5 \%$ among all types of patient and $15.6 \%$ among the diabetics. They also reviewed 4, 108 cases from the literature and claimed that they did not find significant differences in the mortality rate with or without diabetes.

In this country, the mortality rate in Honey and Truelove's (1957) series from the Radcliffe Infirmary was $23.4 \%$ of non-diabetics and $5 \mathrm{I} .4 \%$ of diabetics, respectively.

Bradley and Bryfogle (1956) reported on a series of diabetics only and their mortality rate was $60.8 \%$ of 102 patients. Of the total, I I patients were ketosed on admission and all died. Mintz and Katz (1947) stated that ro of their I9 patients with ketosis died and that the mortality rate amongst those without ketosis was the same as that of the non-diabetics.

Thus the findings of individual investigators vary. No doubt there are several reasons why mortality statistics should vary from different centres, but it is likely that one of the reasons, possibly the predominant one, is that, of the two groups being compared, one, the diabetic, has a peculiar age and sex distribution. Thus it was said that hypertension was more common amongst diabetics until Freedman, Moulton and Spencer (1958) compared an age-matched population with the diabetics and found that hypertension was only more common amongst diabetics over 70 years of age. It is well known that in the over-40 age-group female diabetics considerably outnumber males (Pyke, 1959). In Freedman's series there were 560 female to 260 male diabetics over 40 (i.e. I.9: I), but in the control group of general hospital patients, there were only 733 females to 459 males (i.e. $1.6: 1$ ).

Several studies have shown that the incidence of cardiac infarction correlated with age and the mortality correlated with age differ in the two sexes. Fitzgerald Peel (1955) showed that the incidence of infarction began at an earlier age in males and reached a high peak at ages 55 to 59 , thereafter falling steeply, whereas in females the rise in incidence is slow and steady from 40 to 70 years. In his series the mortality rate in males rose from $5 \%$ at ages less than 44 years to $35 \%$ at ages over 65 years, whereas in females the mortality rate was approximately $25 \%$ in all agegroups, rising only slightly as age increased. The findings of Cole, Singian and Katz (1954) were similar. Mintz and Katz (1947) found the overall mortality higher in females-28.9\% against $18.6 \%$ -but did not compare the different age-groups. Doscher and Poindexter (1950) found the mortality rate in females averaged $50 \%$ higher than males in their own series and this difference increased slightly with age.

Therefore any comparison of the mortality rate of diabetics against that of non-diabetics must take into account the peculiar age and sex distribution of the diabetic population.

\section{Present Investigation}

All cases of cardiac infarction admitted to King's College Hospital from I955 to I959 have been reviewed. The diagnosis has been accepted 
where there has been a suggestive history with typical electrocardiographic changes or raised serum transaminase levels, or, of course, postmortem proof. The deaths recorded are those occurring within 40 days of admission or within 40 days of the infarct if this can be definitely dated before admission.

\section{Results of Investigation}

There were 68 diabetics and 325 non-diabetics in the series. The sex ratio was almost $\mathbf{I}: \mathbf{I}$ (33 males and 35 females) amongst the diabetics, but nearly $3:$ I (24I males against 84 females) amongst the non-diabetics. The mortality rates for the different age-groups are shown in Table $\mathbf{I}$, the percentages being given to the nearest whole number.

TABle I

Males and Females

\begin{tabular}{|c|c|c|c|c|c|c|}
\hline \multirow[b]{2}{*}{ Age } & \multicolumn{3}{|c|}{ Diabetics } & \multicolumn{3}{|c|}{ Non-diabetics } \\
\hline & Total & Died & $\begin{array}{c}\% \\
\text { Died }\end{array}$ & Total & Died & $\begin{array}{c}\% \\
\text { Died }\end{array}$ \\
\hline $30-39$ & 一 & 一 & - & Io & 2 & 20 \\
\hline $40-49$ & 4 & - & - & 54 & 12 & 22 \\
\hline & 20 & 10 & 50 & 91 & 14 & 15 \\
\hline & 23 & 6 & 26 & 109 & 27 & 25 \\
\hline $70-79$ & I 8 & 8 & 44 & 54 & 21 & 39 \\
\hline & 3 & 2 & 67 & 7 & 2 & 29 \\
\hline
\end{tabular}

It can be seen that for each ten-year age-group above 50 years the mortality rate is higher amongst the diabetics. There is, however, an excess of non-diabetics in the age-groups below 50 years and there is a considerable mortality amongst these.

TABLE 2

Males Only

\begin{tabular}{|c|c|c|c|c|c|c|}
\hline \multirow[b]{2}{*}{ Age } & \multicolumn{3}{|c|}{ Diabetics } & \multicolumn{3}{|c|}{ Non-diabetics } \\
\hline & Total & Died & $\begin{array}{c}\% \\
\text { Died }\end{array}$ & Total & Died & $\stackrel{\text { \%o }}{\text { Died }}$ \\
\hline $30-39$ & - & - & - & 6 & - & - \\
\hline $40-49$ & 4 & 一 & - & 48 & 12 & 25 \\
\hline $50-59$ & I3 & 6 & 46 & 77 & 12 & 16 \\
\hline $60-$ & 8 & 3 & 37 & 76 & 23 & 30 \\
\hline $70-79$ & 8 & 4 & 50 & $3 I$ & 14 & 45 \\
\hline & - & - & - & 3 & $\mathbf{I}$ & 33 \\
\hline
\end{tabular}

Tables 2 and 3 show the mortality rates according to age for each sex. It is seen that in all agegroups above 50 years there is a greater mortality amongst the diabetics. The overall mortality amongst the male diabetics-30\%-is approximately the same as that of the female diabetics $-37 \%$, but the latter is greater than that of the non-diabetic males-26\%, with the non-diabetic females having the lowest mortality rate-19\%.
TABLE 3

Females Only

\begin{tabular}{|c|c|c|c|c|c|c|}
\hline \multirow[b]{2}{*}{ Age } & \multicolumn{3}{|c|}{ Diabetics } & \multicolumn{3}{|c|}{ Non-diabetics } \\
\hline & Total & Died & $\begin{array}{c}\% \\
\text { Died }\end{array}$ & Total & Died & $\begin{array}{c}\% \\
\text { Died }\end{array}$ \\
\hline $30-39$ & 一 & 一 & - & 4 & 2 & 50 \\
\hline $40-49$ & - & - & 一 & 6 & - & - \\
\hline $50-59$ & 7 & 4 & 57 & 14 & 2 & 14 \\
\hline $60-69$ & 15 & 3 & 20 & 33 & 4 & 12 \\
\hline $70-79$ & I0 & 4 & 40 & 23 & 7 & 30 \\
\hline $80+$ & 3 & 2 & 67 & 4 & I & 25 \\
\hline
\end{tabular}

Of the diabetics, I3 presented with a raised $\overrightarrow{\vec{\omega}}$ blood-sugar level and/or ketosis (blood sugars $\stackrel{\text { o }}{\circ}$ over $500 \mathrm{mg} . / 100 \mathrm{ml}$. and urine ketones more? than +++ to Rothera's test), but only three of 3 . these died. This mortality rate of $23 \%$ is rather less than the overall figure. Of these 13 patients, four were actually in pre-coma, and only one of 0 these patients died.

A point of interest was that three patients presented in pre-coma with no history of pain, the first symptom being vomiting. Cardiac in- farction was diagnosed by routine electrocardio- $\frac{D}{0}$ graphy following recovery from the episode of pre-coma.

Thirty of the diabetics were obese, i.e. more than $10 \%$ above their expected weight. The. mortality rate amongst these patients was $27 \%$.

In view of the findings of Beckett and Lewis (1960), it is interesting that, in this series, there was only one patient who developed a cardiac infarct during the period of weight loss following the institution of dietary treatment, and he had had angina for two years previously.

\section{Discussion}

It is possible to criticize the comparison between the two groups on the grounds that general practitioners are more likely to seek the admission of a diabetic with a cardiac infarct as soon as possible after the episode, and that more nondiabetics are therefore likely to die before admission is arranged or sought, thus reducing the hospital mortality figures. However, if this be the case, there should be a preponderance of less severe infarcts among the diabetics, which would tend to reduce the diabetic mortality rate. In fact, about two-thirds of the deaths in each group occurred within 48 hours of admission, which would suggest that there is no difference in selection.

The findings conflict with those of most other investigators with regard to the lower mortality among the non-diabetic females compared with the non-diabetic males. However, the figures support the view that diabetes worsens the prog- 
nosis after cardiac infarction, and that this is so for both sexes and for all ages above 50 years. The paucity of diabetics under the age of 50 in this series suggests that diabetes plays little part in the ætiology of ischæmic heart disease in the younger age-groups.

The finding of the relatively lower mortality rate among the diabetics with both cardiac infarction and ketosis is surprising, as the combination would have been expected to be particularly unfavourable, as both Mintz and Katz (1949) and Bradley and Bryfogle (1956) found. On the other hand, whereas one can usually give a confidently good prognosis in a case of diabetic coma or pre-coma, the possibility of cardiac infarction as a cause must lead to a much more guarded prognosis. It is, of course, possible for the circulatory disturbances of diabetic coma to precipitate a cardiac infarction (Bradley and Bryfogle, 1956), but in the three patients in this series who gave no history of pain prior to the upset in their diabetes, no other cause for the episode could be found and it was thought more likely that the infarct preceded the ketosis. In either case, it should be routine for electrocardiography to be carried out in patients over 40 years of age who develop severe ketosis or acidosis.

In this series the presence of obesity does not appear to have adversely influenced the prognosis in the diabetics.

\section{Summary}

I. A review of 68 diabetics and 325 nondiabetics with cardiac infarction admitted to King's College Hospital from 1955 to 1959 is presented. The overall mortality was greater amongst the diabetics and was also greater when the two sexes were compared overall and for each ten-year age-group over 50 years.

2. The prognosis for the diabetics was not worsened by the presence of ketosis nor by the association of obesity.

3. The possibility of cardiac infarction both as a cause and as a result of diabetic pre-coma or coma is noted.

I am grateful to the physicians of King's College Hospital for permission to report on their patients and to Dr. W. G. Oakley for permission to report and for advice during the preparation of this paper.

\section{REFERENCES}

Beckett, A. G., and Lewis, J. G. (1960): Mobilization and Utilization of Body Fat as an Ftiological Factor i Osclusive Vascular Disease in Diabetes Mellitus, Lancet, ii, 14.

Bradeey, R. F., and Bryfogle, J. W. (1956): Survival of Diabetic Patients after Myocardial Infarction, Amer. Y. Med. 20, 207.

Cole, D. R., Singian, E. B., and Katz, L. N. (1954): The Long-term Prognosis following Myocardial Infarction and Some Factors which Affect It, Circulation, 9, $32 \mathrm{I}$.

Doscher, N., and Poindexter, C. A. (1950): Myocardial Infarction without Anticoagulant Therapy, Amer. Y. Med. 8,623 .

Freediuan, P., Moulton, R., and SpencrR, A. G. (1958): Hypertension and Diabetes Mellitus, Quart. F. Med., 27, 293.

HoNey, G. E., and Truelove, S. C. (1957): Prognostic Factors in Myocardial Infarction, Lancet, i, Ir 55.

Katz, L. N., Mills, G. Y., and Cis.nezos, F. (1949): Survival after Recent Myocardial Infarction, Arch. intern. Med., 84, 305 .

Mrviz, S. S., and Katz, L. N. (1947): Recent Myocardial Infarction, Ibid., 80, 205.

Pegc, F. (1955): Age and Sex Factors in Coronary Artery Disease, Brit. Heart f., 17, 319.

PYKB, D. A. (1959): Ætiological Faciors in Diabetes, Postgrad. med. F., 35, 261.

Wood, P. (1955): 'Diseases of the Heart and Circulation', 2nd edition. London: Eyre \& Spottiswoode. 